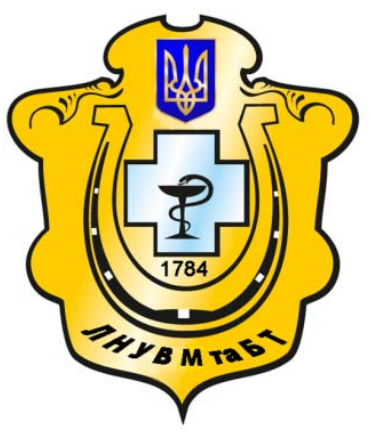

Науковий вісник Львівського національного університету ветеринарної медицини та біотехнологій імені С.3. Гжицького

Scientific Messenger of Lviv National University of Veterinary Medicine and Biotechnologies named after S.Z. Gzhytskyj

doi:10.15421/nvlvet6822

ISSN 2413-5550 print

ISSN 2518-1327 online

$\underline{\text { http://nvlvet.com.ua/ }}$

УДК 664.9

\title{
Високотемпературне рентгенографічне дослідження теплових властивостей кристалічних тіл
}

\author{
Я.І. Федишин ${ }^{1}$, Д.І. Вадець ${ }^{2}$, Т.Я. Федишин ${ }^{1}$ \\ fedyshyn.yaroslav@gmail.com
}

\begin{abstract}
${ }^{1}$ Львівський національний університет ветеринарної медицини та біотехнологій імені С.3. Гэсицького, вул. Пекарська, 50, м. Львів, 79010, Україна;

Національний університет водного господарства і природокористування,
\end{abstract} вул. Соборна, 1, м. Рівне, 33028, Украӥна

\footnotetext{
Розглянуто експериментальні дослідження теплових фізичних характеристик кубічних кристалів високотемпературним методом.

Високотемпературний рентгенівський метод має істотну перевагу, бо, використовуючи його, ми самостійно без додаткових даних про речовину (які дуже часто одержані різними методами з використаннями різних моделей) визначаємо низку важливих характеристик динаміки кристалічних граток речовини.

Це єдина методика високотемпературного рентгенографування, застосована при дослідженнях, особливо доиільна при порівнянні фізичних властивостей кристалів у фазах ізоструктурних сполук певного класу (або ряду твердих розчинів металів) з певним типом кристалічних граток, структур типу $\mathrm{NaCl}, \mathrm{CsCl}, \mathrm{Ca} B_{6}, \mathrm{UB}_{12}$ та інварних і пермалойних сплавів.

Одержані залежності періодів кристалічних граток, коефіцієнтів термічного розширення, рентгенівської характеристичної температури та середньоквадратичних динамічних ( зміщень. Вперие проведено систематичне високотемпературне рентгенографічне дослідження ізоструктурних сполук кубічних гексаборидів $\mathrm{MeB}_{6}$ і додекаборидів $\mathrm{MeB}_{12}$. Встановлено, щчо для гексаборидів і додекаборидів ангармонізм теплових коливань атомів кристалічних граток зумовлений явною температурною залежністю $\theta_{\mathrm{p}}(T)$, а не об'ємним розщиренням кристалічної гратки, як у випадку іонних кристалів. Абсолютні значення при кімнатній температурі для гексаборидів порядку $700 \mathrm{~K}$, а для додекаборидів вище $800^{\circ} \mathrm{K}$. Показано, щьо узагальнююча міра ангармонізму $\frac{d \ln \theta_{p}}{d T}$ для додекаборидів $(0,09 \div 0,13) \cdot 10^{-3} \cdot K^{-1}$. Амплітуди теплових коливань атомів у гратках додекаборидів менші, ніж у гексаборидів, $i$ значно менші у гратках чистих металів. Це вказує на високу міцність міжатомних зв'язків у гратках додекаборидів, які можуть використовуватися у жаростійких виробництвах.

У перспективі ми готуємось до майже «безпосереднього» визначення $\overline{u_{g}^{2}}$, а не через значення $\theta_{p}$.

Ключові слова: рентгенівські промені, характеристична температура, середньоквадратичні динамічні зміщення, інтерференційні максимуми, множники інтенсивності, структурний фактор.
}

\section{Высокотемпературное, рентгенографическое исследование тепловых свойств кристаллических тел}

\author{
Я.И. Федышин ${ }^{1}$, Д.И. Вадец², Т.Я. Федышин ${ }^{1}$ \\ fedyshyn.yaroslav@gmail.com \\ ${ }^{1}$ Львовский нацчиональный университет ветеринарной медиияны и биотехнологий имени С.3. Гжицєкого, \\ ул. Пекарская, 50, г. Львов, 79010, Украина; \\ ${ }^{2}$ Национальный университет водного хозяйства и природопользования \\ ул. Соборная, 11, г. Ровно, 33028, Украина
}

Citation:

Fedyshyn, Y.I., Vadets, D.I., Fedyshyn, T.Y. (2016). High temperature, radiographic research of thermal properties of crystalline solids. Scientific Messenger LNUVMBT named after S.Z. Gzhytskyj, 18, 2(68), 111-114. 
Рассмотрены экспериментальные тепловых физических характеристик физических кристаллов высокотемпературным методом. Высокотемпературный рентгеновский метод имеет то важное преимущество, что следуя ему, можна самостоятельно без дополнительных данных о веществе (которые зачастую получены различными методами с использованием моделей) определяем ряд важных характеристик динамики кристаллических решеток веществ. Единая методика высокотемпературного рентгенографирования, применённая при исследованиях, особенно целесообразна при сравнении физических свойств при фазах изоструктурных соединений определённого класса или ряда твёрдых растворов металлов), обладающих определённым типом кристаллических решеток, структур типа $\mathrm{NaCl}$, CsCl, CaB ${ }_{6}$, и инварных и пермаллойных сплавов. Получены зависимости периодов кристаллических решеток, коэффициентов термического расиирения, рентгеновской характеристической температуры и среднеквадратичных динамических (и статических в инварных и пермаллойных сплавах) смещений. Впервые проведено систематическое высокотемпературная рентгенографическое

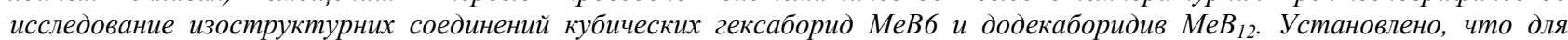
гексаборид и додекаборидив ангармонизм тепловых колебаний атомов кристаллической решетки обусловлен явной температурной зависимости $\theta_{\perp}$ (T), а не объемным расширением кристаллической решетки, как в случае ионных кристаллов.

Абсолютные значения при комнатной температуре для гексаборид порядке $700 \mathrm{~K}$, а для додекаборидов выше $800{ }^{\circ} \mathrm{K}$.

Показано, что обобщуающая мера ангармонизма $\left(\frac{d \ln \theta_{p}}{d T}\right)$ для додекаборидов - $(0,09 \div 0,13) \cdot 10^{-3} \cdot K^{-1}$.

Амплитуды тепловых колебаний атомов в решетке додекаборидов меньше, чем в гексаборид, и значительно меньше в решетке чистых металлов. Это указывает на высокую прочность межатомных связей в решетке додекаборидив, которые могут использоваться в жаростойких производствах.

В перспективе мы готовимся к почти «непосредственного» определение $\overline{u_{g}^{2}}$, а не через значение $\theta_{p}$.

Ключевые слова: рентгеновские лучи, характеристическая температура, среднеквадратичные динамические смещения, интерференционные максимумы, множители интенсивности, структурный фактор.

\title{
High temperature, radiographic research of thermal properties of crystalline solids
}

\author{
Y.I. Fedyshyn ${ }^{1}$, D.I. Vadets ${ }^{2}$, T.Y. Fedyshyn ${ }^{1}$ \\ fedyshyn.yaroslav@gmail.com \\ ${ }^{1}$ Lviv National University of Veterinary Medicine and Biotechnologies named after S.Z. Gzhytskyi, \\ Pekarska Str., 50, Lviv, 79010, Ukraine; \\ National university of water resources and environmental Sciences, \\ Soborna Str., 11, Rivne, 33028, Ukraine
}

\begin{abstract}
It was considered experimental research of thermal physical characteristics of cubic crystals with the help of high temperature method.

High temperature X-ray method has a significant because we are using it independently without any of the substance (which are often produced by different methods using different models), define several important characteristics of the dynamics of crystal lattices of the substance. This is the only method of high X-ray columning applied in research is particularly appropriate when comparing the physical properties of crystals in phases of structural compounds of a certain class (or a number of solid solutions of metals) with a certain type of crystal lattices, structures and type $\mathrm{Na} \mathrm{Cl}, \mathrm{CsCl}, \mathrm{CaB}{ }_{6}, \mathrm{UB}_{12}$ and invarian and permaloic alloys.

Obtained periods depending on crystal lattices, the coefficients of thermal expansion, X-ray characteristic temperature and mean-square dynamical (and statistical in invariant and permaloid alloys) bias.

For the first time It was performed a systematic search of high-temperature X-ray isostructural compounds of cubic hexaboride MeB6 and dodekaborides $M e B_{12}$. It was established that hexaboride and dodekaborides, anharmonicity of atoms thermal vibrations of crystal lattices is caused by the apparent of temperature dependence $\theta r(T)$, rather than voluminous lattice expansion as in the case of ionic crystals.

The absolute value at room temperature for hexaboride is about $700^{\circ} \mathrm{C}$, and for dodekaborides is above $800{ }^{\circ} \mathrm{C}$.

It is shown that generalized measure of anharmonicity dln $\theta p d T$ for dodekaborides $-(0,09 \div 0,13) \cdot 10-3 \cdot K-1$. The amplitudes of thermal vibrations of atoms in lattices of dodekaborides are less than in hexaboride and much less than in the lattices of pure metals. This indicates very strong interatomic bonds in dodekaborides lattices that can be used in heat-resistant industries. In the future, we are preparing to almost «immediate» definition of ug2, not through value $\theta p$.
\end{abstract}

Key words: X-rays characteristic temperature, mean-shift dynamic, interference maxima, intensity factors, structural factors.

\section{Вступ}

Експериментальні дослідження фізичних характеристик динаміки кристалів завжди мали актуальне значення, особливо - коли мова йде про малодосліджені композитні речовини. Такі дослідження ведуться різними методами та методиками.

Нами вибраний високотемпературний кубічної сингонії. Рентгенографічний метод дослідження теплових властивостей не потребує значень експериментальних даних, одержаних іншими методами, наприклад даних постійної $\gamma$ Грюнайзена, температурної залежності параметра кристалічної гратки, коефіцієнта об'ємного розширення, значення характеристичної температури $\theta_{\mathrm{p}}$ Дебая тощо. Ці та інші величини можна визначити рентгенівським способом. 
Цей метод вперше системно розвинутий школою науковців Чернівецького університету. Вони теоретитеоретично і експериментально пов'язали, наприклад, рентгенівську характеристичну температуру Дебая $\theta_{\mathrm{p}}$ 3 ангармонізмом теплових коливань атомів кристалічної гратки, ввели узагальнюючу кількісну міру ангармонізму коливань:

$$
\frac{d \ln \theta_{\mathrm{p}}}{d T}=-n \gamma \beta
$$

де $T$ - термодинамічна температура, $\gamma$ - стала Грюнайзена, $\beta$ - термічний коефіцієнт об'ємного розширення, $n$ - безрозмірний параметр ( в загальному випадку не завжди рівний двом).

Ми підтримали розробки цього напряму науковців Чернівецького університету. Зокрема підтримали методику Чіпмена (Chipman, 1960) щодо визначення $\theta_{\mathrm{p}}$ при низьких температурах за сімейством кривих $\theta_{\mathrm{p}}(\mathrm{T}) \quad 3$ врахуванням поправок на температурне дифузне розсіювання (ТДР) рентгенівських променів (Chipman and Paskin, 1959).

Для цього ми вдосконалили високотемпературну приставку до стандартної камери рентгенівського оберненого знімання (КРОС) із забезпеченням знаходження плоского досліджуваного зразка у вакуумі або в інертному середовищі i термостатування шляхом повітряного i водяного охолодження та одержання 12 або 24 кросограм на одній плівці при різних температурах в інтервалі (273 $\div 1073)$ К та різних концентраціях твердих розчинів. Плоский досліджуваний зразок міг коливатись в площині, перпендикулярній до первинного рентгенівського променя.

У ранніх роботах ми обмежились рентгенографічним методом дослідження. Для врахування нестабільності режиму роботи рентгенівської трубки застосовувалась додаткова касета $з$ плівкою, на яку фіксувались інтерференційні максимуми незалежного еталона інтенсивності.

Для визначення інтегральної інтенсивності дифракційних максимумів кожна рентгенограма фотометрувалась 3 обох сторін на мікрофотометрі МФ-4. За допомогою інтегрального планіметра знаходилась площа, обмежена кривою почорніння i лінією фону.

Виміряну величину відносної інтегральної інтенсивності лінії від зразка і, відповідно, еталона отримували за співвідношенням

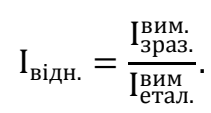

Як відомо, теплові коливання атомів кристалічної гратки призводять до послаблення інтенсивності рентгенівських інтерференційних максимумів за відомим співвідношенням (Mirkin, 1961)

$$
\mathrm{I}(\mathrm{T})=g P L G p \cdot F^{2} A(v) \cdot e^{-2 M},
$$

де $g$ - коефіціснт пропорційності, який залежить від інтенсивності падаючого первинного променя, числа елементарних комірок в одиниці об'єму опроміненої досліджуваної речовини; $P$ - поляризаційний фактор; $L$ - фактор Лоренца; $G$ геометричний множник; $p$ - фактор повторюваності; $A(v)$ - абсорбційний множник; $v$ - брегівський кут дифракції; $F-$ структурний фактор; $e^{-2 M}-$ температурний множник (фактор Дебая - Валлера).

Температурний множник можна виразити через характеристичну температуру $\theta$ або величину середньоквадратичного зміщення $\overline{u^{2}}$ атомів від положення рівноваги:

$$
\exp [-2 M(T)]=\exp \left\{-\frac{12 h^{2}}{m k^{\theta}}\left[\frac{\phi\left(\frac{\theta}{T}\right)}{\frac{\theta}{T}}+\frac{1}{4}\right] \frac{\sin ^{2} v}{\lambda^{2}}\right\}
$$

або

$$
\exp [-2 M(T)]=\exp \left\{-\frac{16}{3} \pi^{2} \overline{u^{2}} \frac{\sin ^{2} v}{\lambda^{2}}\right\}
$$

де $m$ - маса атома, $k$ - стала Больцмана, $h$ - стала Планка, $\lambda$ - довжина хвилі рентгенівських променів.

Формулу (3) можна переписати як

$$
\mathrm{I}(\mathrm{T})=\mathrm{K}_{\mathrm{T}} e^{-2 M},
$$

де $\mathrm{K}_{\mathrm{T}}$ - добуток всіх множників інтенсивності, крім дебаєвського, а

$$
\begin{array}{r}
2 \mathrm{M}=-\frac{12 h^{2}}{m k} \cdot \frac{\sin ^{2} v}{\lambda^{2}}\left\{\frac{\mathrm{T}}{\theta^{2}}\left[\phi\left(\frac{\theta}{T}\right)+\frac{\theta}{4 \mathrm{~T}}\right]\right\} \\
=\frac{12 h^{2}}{m k} \cdot \frac{\sin ^{2} v}{\lambda^{2}} \cdot \frac{T \psi}{\theta^{2}} .
\end{array}
$$

Логарифм відношення інтегральних інтенсивностей інтерференційного максимуму даного відбивання (hkl) при температурах $\mathrm{T}$ i $\mathrm{T}_{0}$ (наприклад, кімнатній) має вигляд:

$$
\ln \frac{\mathrm{I}}{\mathrm{I}_{0}}=\ln \frac{\mathrm{K}}{\mathrm{K}_{0}}+\frac{12 h^{2}}{m k}\left[\frac{T_{0} \psi_{0}}{\theta_{0}^{2}} \cdot \frac{\sin ^{2} \mathcal{V}}{\lambda^{2}}-\frac{T \psi}{\theta^{2}} \cdot \frac{\sin ^{2} \mathcal{V}}{\lambda^{2}}\right]
$$

або

$$
\ln \frac{\mathrm{I}}{\mathrm{I}_{0}}=\ln \frac{\mathrm{K}}{\mathrm{K}_{0}}+\frac{3 h^{2}}{m k} \cdot \sum_{j} h_{j}^{2}\left[\frac{T_{0} \psi_{0}}{a_{0}^{2} \theta_{0}^{2}}-\frac{T \psi}{a^{2} \theta^{2}}\right],
$$

де $\sum_{j} h_{j}^{2}$ - сума квадратів мюлерівських індексів (hkl) для кубічних кристалів.

Якщо врахувати поправки на температурне дифузне розсіювання (ТДР), то вираз (9) прийме вигляд:

$$
\ln \frac{\mathrm{I}}{\mathrm{I}_{0}}=\ln \frac{\mathrm{K}}{\mathrm{K}_{0}}+\frac{3 h^{2}}{m k} \cdot \sum_{j} h_{j}^{2}\left[\frac{T_{0} \psi_{0}}{a_{0}^{2} \theta_{0}^{2}} \cdot\left(1-\beta_{0}\right)-\frac{T \psi}{a^{2} \theta^{2}} \cdot(1-\beta)\right],(10)
$$

де для ГЦК граток (Chipman and Paskin, 1959)

$$
\beta=\left(\frac{\pi}{3}\right)^{\frac{1}{3}} \frac{a \Delta v \cdot \cos v_{0}}{2 \lambda},
$$

а для ОЦК граток (Chipman and Paskin, 1959) 


$$
\beta=\left(\frac{2 \pi}{3}\right)^{\frac{1}{3}} \frac{a \Delta v \cdot \cos v_{0}}{2 \lambda},
$$

де $a$ - період кристалічної гратки, $\Delta v-$ кутова ширина фотометричної кривої лінії почорніння (hkl), $v_{0}$ - брегівський кут центра кривої, $\lambda$ - довжина хвилі рентгенівського променя.

Величина $K(\mathrm{~T})$, а точніше $\ln \frac{\kappa}{\mathrm{K}_{0}}$, розраховується за визначеними періодами кристалічної гратки та за брегівськими кутами $v$ (Mirkin, 1961).

Величина $\psi$ рівна

$$
\psi(x)=\phi\left(\frac{\theta}{T}\right)+\frac{\theta}{4 T}
$$

може бути виражена (з точністю не нижче 0,1\%) рядом (Dzhejms, 1961)

$$
\psi(x)=\phi(x)+\frac{x}{4} \approx 1+\alpha x^{2} .
$$

Розв'язуючи сумісно рівняння (10) і (14) відносно $\theta(\mathrm{T})$, отримаємо:

$$
\begin{gathered}
\theta_{i}^{2}=\frac{3 h^{2} \sum_{j} h_{j}^{2} T_{i}\left(1-\beta_{i}\right)}{m k}\left\{\frac { 3 h ^ { 2 } \sum _ { j } h _ { j } ^ { 2 } } { m k } \left[\frac{T_{0}\left(1+\beta_{0}\right)\left(1+\alpha \frac{\theta_{0}^{2}}{T_{0}^{2}}\right) a_{i}^{2}}{a_{0}^{2} \theta_{0}^{2}}\right.\right. \\
\left.\left.-\frac{\alpha\left(1-\beta_{i}\right)}{T_{i}}\right]-\left(\ln \frac{I_{i}}{I_{0}}-\ln \frac{K_{i}}{K_{0}}\right) a_{i}^{2}\right\}^{-1}, \quad \text { (1) }
\end{gathered}
$$

де індекси «0» та «i» відносять фізичні величини до кімнатної $\mathrm{T}_{0}$ i температури $T_{i}>T_{0}$.

Оскільки $\theta_{i}(T)$, визначена за формулою (15), дуже чутлива до вибору $\theta_{0}$, то для визначення достовірної залежності $\theta(\mathrm{T})$ у формулу слід підставляти орієнтовно декілька значень $\theta_{0} 3$ інтервалом $5 \div 15 \mathrm{~K}$. При цьому отримується сімейство кривих $\theta(\mathrm{T})$. Найбільш достовірною залежністю $\theta(\mathrm{T})$ є крива, яка найменш змінюється в області низьких (наприклад, кімнатних) температур.

Цей метод ми застосували при високотемпературному дослідженні простих речовин $(\mathrm{Cu}, \mathrm{Ni}, \mathrm{Fe})$, а потім перенесли його при дослідженні іонних кристалів типу $\mathrm{NaCl}$ i CsCl. Результати досліджень добре корелюють 3 даними інших дослідників. Це дало нам можливість поширити цей метод при дослідженні сплавів системи $\mathrm{Cu}-\mathrm{Ni}, \mathrm{Fe}-$ $\mathrm{Ni}, \mathrm{KCl}-\mathrm{KBr}$ та ряду більш складних кубічних структур типу $\mathrm{CaB}_{6} \mathrm{i} \mathrm{UB}_{12}$

За наявності експериментальних рентгенографічних даних для всіх об'єктів дослідження одержані дані температурної залежності параметра кристалічної гратки $a(t)$, інтенсивності одного дифракційного максимума I(T), рентгенівської характеристичної температури Дебая $\theta_{p}(T)$, залежності середньоквадратичних динамічних зміщень $\overline{u_{g}^{2}}(T)$ та $\sqrt{\overline{u_{g}^{2}}}(T)$, залежності середніх і дійсних коефіцієнтів розширення $\alpha(\mathrm{T})$, оцінені постійні Грюнайзена, за рентгенівськими даними розраховані швидкості поширення звуку в досліджуваних об'єктах, оцінені ангармонічні коефіцієнти III і IV порядків тощо. Всі розрахунки велись на електронно-обчислювальній машині «Промінь», а пізніше перевірені на сучасних комп'ютерах.

\section{Висновки}

Вперше проведено систематичне високотемпературне рентгенографічне дослідження ізоструктурних сполук кубічних гексаборидів $\mathrm{MeB}_{6} \mathrm{i}$ додекаборидів $\mathrm{MeB}_{12}$.

Встановлено, що для гексаборидів і додекаборидів ангармонізм теплових коливань атомів кристалічних граток зумовлений явною температурною залежністю $\theta_{\mathrm{p}}(T)$, а не об'ємним розширенням кристалічної гратки, як у випадку іонних кристалів.

Абсолютні значення при кімнатній температурі для гексаборидів порядку 700 К, а для додекаборидів вище $800 \mathrm{~K}$.

Показано, що узагальнююча міра ангармонізму $\frac{d \ln \theta_{p}}{d T}$ для додекаборидів - $(0,09 \div 0,13) \cdot 10^{-3} \cdot K^{-1}$.

Амплітуди теплових коливань атомів у гратках додекаборидів менші, ніж у гексаборидів, і значно менші у гратках чистих металів. Це вказує на високу міцність міжатомних зв'язків у гратках додекаборидів, які можуть використовуватися у жаростійких виробництвах.

у перспективі ми готуємось до майже «безпосереднього» визначення $\overline{u_{g}^{2}}$, а не через значення $\theta_{p}$

\section{Бібліографічні посилання}

Chipman, D.R. (1960). J. Appl.Phys. 31, 2012-2015.

Chipman, D.R., Paskin, A. (1959). J. Appl. Phys. 30, 12, 1992.

Mirkin, L.I. (1961). Spravochnik po rentgenostrukturnomu analizu polikristallov. Moskwa: Fizmatgiz. (in Russian).

Dzhejms, R. (1961). Opticheskie principy difrakcij rentgenovskih polikristallov. Moskwa (in Russian).

Fedyshin, Ja.I., Mikolajchuk, A.G., Vadec, D.I., Martynjuk, V.D. (1982). Izv. AN SSSR s. Neorganicheskie materialy. 18 (8), 1312 (in Russian).

Vadec, D.I., Giller, Ja.L., Kavich, I.V., Fedyshin, Ja.I. (1970). Izv. vuzov, s. fizika. 12, 160 (in Russian).

Fedyshin, Ja.I. (1972). Sb. Jelektronnaja tehnika. Materialy. 10, 121 (in Russian).

Fedyshin, Ja.I., Dutchak, Ja.I., Paderno, Ju.B., Vadec, D.I. (1972). Sb. Jelektronnaja tehnika/ Materialy, 4, 117 (in Russian). 